\section{Your Genes: Getting the Best Fit}

Germline testing for inherited susceptibility to cancer seems to be gaining more and more traction. Of course, we always recommended testing for patients in whom we suspected mutations based on personal and family history. But what about all those apparently sporadic cancers? How often is an underlying mutation driving the development of the disease?

Recently, researchers at Johns Hopkins University reported on the incidence of these mutations in patients with pancreatic cancer and unremarkable family histories. ${ }^{1}$ Surprisingly, the incidence was 3.9\%-much higher than anyone would have anticipated - and the mutations found spanned the spectrum of inherited cancer syndromes. Of course, it's still a small number, but think about the implications for other family members who, if found to be carriers, could tailor their screening to improve the chance for early detection. And of course, testing now has important implications for the patient. We now have new treatment options, such as PARP inhibitors for patients with BRCA1/2 mutations or pembrolizumab for patients with Lynch syndrome. Even standard of care can be influenced, such as the choice of DNAdamaging agents like cisplatin for patients who have a mutation that affects DNA repair, or avoidance of radiation in those with $\mathrm{Li}$-Fraumeni syndrome. So the stakes are higher now than ever before.

With all the buzz about new therapies and more dissemination of information about cancer-causing genes, patients and the public at large are getting more interested in knowing whether they carry cancer-prone mutations. I was at a public education session about this topic recently. Admittedly, individuals came to listen because they were interested, so the group was a bit biased. But I think if we had offered on-site testing, everyone would have lined up!

It got me thinking about how we as a society deal with this in a reasonable, costeffective, and responsible manner. After all, we don't want a sea of worried well people with known mutations clamoring for tests and diagnostic procedures that could do them more harm than good. Yet, there is so much we don't know. For example, how do you select the BRCA-positive family that also needs specialized screening for pancreatic or prostate cancer? What do we do with variants of unknown significance? Can we ever really figure out whether a given variant might be significant?

And who can help these people navigate their cancer risk and select cost-effective, minimal-risk screening strategies while reducing lifestyle risks that they can actually control? Considering the expanding need, the workforce shortage in genetic counseling is increasing to epic proportions, and I don't think there is a solution in sight.

So I guess this is another call to action. Understanding our genetic makeup has real implications for our health, and the public will be increasingly insistent that this information be as available as their cholesterol level. And, as with everything else, this will require a major investment—in research to provide the evidence we need, in training to produce the talented workforce required, and in education to help the public rein in fear and exchange it for power.

\section{Reference}

1. Shindo $\mathrm{K}, \mathrm{Yu} J$, Suenaga $M$, et al. Deleterious germline mutation in patient with apparently sporadic pancreatic adenocarcinoma [published online ahead of print August 2, 2017]. J Clin Oncol 2017, doi:10.1200/ JCO.2017.72.3502.

What do you think? Please e-mail correspondence (include contact information) to JNCCN@nccn.org or log into www.editiorialmanager.com/JNCCN to submit a Letter to the Editor.

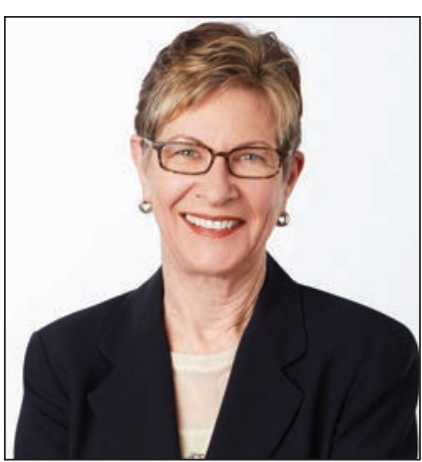

Margaret Tempero, MD

Margaret Tempero, MD, is a Professor of Medicine and Director of the UCSF Pancreas Center and editor-in-chief of JNCCN. Her research career has focused on pancreatic ductal adenocarcinoma, especially in the area of investigational therapeutics. Dr. Tempero has served on the ASCO Board of Directors and as ASCO President. She currently serves on the ASCO Conquer Cancer Foundation Board. She codirected the AACR/ASCO Methods in Clinical Cancer Research and taught this course and similar courses in Europe and Australia. She was founding Chair of the $\mathrm{NCl}$ Clinical Oncology Study Section and served as a member and Chair of the NCl Board of Scientific Counselors Subcommittee A. She is a member of the Scientific Steering Committee and Chair of the Clinical and Translational Study Section for the Cancer Prevention \& Research Institute of Texas. She is or has been on the Scientific Advisory Boards of the Lustgarten Foundation, the Pancreatic Cancer Action Network, the V Foundation, The Alberta Canada Cancer Board, and the EORTC. She served as a member of the Oncology Drug Advisory Committee for the FDA. She has served as Deputy Director and Interim Director for the UNMC Eppley Cancer Center. She is Chief Emeritus of the Division of Medical Oncology at UCSF and served as the founding Deputy Director and Director of Research Programs at the UCSF Helen Diller Family Comprehensive Cancer Center.

doi:10.6004/jnccn.2017.0152

The ideas and viewpoints expressed in this editorial are those of the author and do not necessarily represent any policy, position, or program of NCCN. 